\title{
Representar la democracia en dictadura: los partidos políticos en Argentina en los albores de la transición
}

\author{
Representing democracy under dictatorship: political parties at the \\ dawn of the argentinian transition
}

Adrián Velázquez velaram@gmail.com

http://orcid.org/0000-0002-1417-682X

Instituto de Altos Estudios Sociales;

Universidad Nacional de San Martín (Argentina)

\begin{abstract}
Resumen
El presente artículo aborda el periodo que transcurre entre 1980 y 1983 y se propone reconstruir el proceso que antecede a la apertura democrática concretada el 10 de octubre de 1983 en la Argentina. El objetivo es mostrar la semántica que se condensó alrededor de la dicotomía democracia/dictadura y que luego de la derrota militar en Malvinas se constituyó como una referencia ineludible del espacio político argentino. Para ello, indagamos en las concepciones que orientaron la práctica representativa de los partidos políticos, centrándonos primordialmente en la Unión Cívica Radical y el Partido Justicialista.
\end{abstract}

Palabras clave: Transición a la democracia; dictadura; Argentina; partidos políticos; representación política. 
Abstract

This article discusses the period between 1980 and 1983 and aims to rebuild the process that precedes the democratic opening that took place on October 10, 1983 in Argentina. The objective is to show the semantics that were condensed around the dichotomy democracy/dictatorship and that after the military defeat in Malvinas was constituted as an inescapable reference of the Argentine political space. To this end, we investigated the conceptions that guided the representative practice of political parties, focusing primarily on the Radical Civic Union and the Peronist Party.

Keywords: Transition to democracy; dictatorship; Argentina; political parties; political representation.

"Lo que caracteriza la experiencia democrática es esa facultad de imaginar el juego político" Claude Lefort

Sin que fuera su objetivo, la convocatoria al dialogo político realizada por el presidente de facto Jorge Rafael Videla hacia el final de su mandato, puso en marcha un proceso de reorganización partidaria. Con la expectativa de una próxima apertura política, el arco civil partidario ensayó diferentes posicionamientos que variaron a medida que los intentos de concertación fracasaron. El rápido ocaso de la última dictadura militar en Argentina (19761983) ha tendido a relegar este proceso. El énfasis puesto en la implosión del gobierno de facto luego del fracaso bélico en las islas del Atlántico Sur ha relativizado el papel de los partidos políticos durante estos años (1). Sin embargo, el periodo que va de 1980 a 1983 resulta importante para dimensionar los cambios que trajo consigo la transición a la democracia en la Argentina. En este artículo nos interesa reconstruir este proceso de reacomodo partidario marcando diferentes puntos de pasaje en los cuales el concepto de democracia se fue cargando de una semántica particular.

Una de las características de la transición a la democracia argentina es que vino acompañado de un discurso que interpretó aquel momento como una ruptura. Este discurso se mostró eficaz para darle significación al curso de los hechos y en muchos sentidos marcó los límites del espacio político argentino durante el gobierno de Raúl Alfonsín (1983-1989). El éxito de este 
discurso tiene como corolario, sin embargo, que en torno a la apertura política de 1983 se haya edificado una frontera que divide de forma simétrica los hechos que forman parte de la dictadura de aquellos que lo hacen de la transición propiamente dicha. De esta manera, al fijar su propia génesis en una ruptura, el discurso de la transición es capaz de establecer sus propias condiciones de validez: la ruptura es explicada a partir de las propias premisas discursivas que la crean. En tanto discurso de ruptura, la transición a la democracia tiende a eludir la reflexión sobre sus condiciones previas, pues esta no se explica a sí misma desde ahí, sino en la confirmación de su efecto rupturista; es decir, en su radical diferencia respecto a lo que dejó atrás y que terminó por inscribir el concepto dictadura dentro de un campo semántico particular. Proponemos, por lo tanto, tomar el camino inverso y preguntarnos por las condiciones que hicieron posible enunciar dicha ruptura. Nuestro interés por el periodo 19801983 no es tanto negar o introducir un matiz respecto de dicha ruptura sino mostrar las condiciones de posibilidad de un discurso que interpretó la apertura de 1983 bajo estos términos.

Para 1983, el espacio político argentino pasó a organizarse en torno a dos cadenas de equivalencia antagónicas. Por un lado, se va tejiendo una interpretación que vincula a la dictadura con el favorecimiento de los intereses de una minoría económica y las secuelas de la represión estatal. Por el otro, el concepto de democracia pasa a relacionarse con la defensa de los intereses de las mayorías populares y a la posibilidad de dar una respuesta al problema de los desaparecidos. Para dar cuenta del proceso por el cual este juego de equivalencias emerge es importante comprender los sentidos que orientaron la práctica representativa de los partidos políticos. ¿Bajo qué términos y condiciones estos partidos se imaginaban el juego político ante una ciudadanía que entre 1966 y 1980 había experimentado tres años de gobierno democrático? ¿Qué mandatos decían estar representando a su nombre?

Proponemos, por lo tanto, abordar estos interrogantes teniendo en cuenta la historicidad de los mandatos que los actores políticos partidarios consideran representar ante sus electores. Consideramos que esta alternativa ofrece una vía de acceso singular a los procesos mediante los cuales se organiza el juego político. En este sentido, la representación política resulta un mecanismo social fundamental en tanto permite a hacer inteligibles los estados de ánimo públicos a través de la producción de narrativas políticas que pugnan por darle una adecuada significación al curso de los hechos (2). Es a partir de la representación política que el concepto de democracia se va cargando de un contenido histórico concreto y en torno al cual edificará una frontera respecto al pasado dictatorial (Aboy Carlés, 2001). 
Para comenzar es necesario establecer cómo es formulado el problema de la representación política dentro del diagnóstico desde el cual la última dictadura militar -autodenominada como Proceso de Reorganización Nacional (PRN)- buscó justificar su proyecto refundacional. Esta interpretación condicionó la dinámica de los partidos políticos de cara a la fase de institucionalización proyectada por la Junta Militar en 1979, año en que se publican las Bases Políticas de las Fuerzas Armadas para la Reorganización Nacional (3).

\section{El Proceso: crítica al populismo y proyecto refundacional}

El gobierno militar que llegó al poder tras el golpe de Estado de marzo de 1976 reivindicó su accionar al postularse como un mecanismo de salvaguarda ante la crisis de violencia política que experimentaba el país. Sin embargo, de ninguna manera las Fuerzas Armadas limitaron su intervención a esta cuestión. Por el contrario, dentro del diagnóstico militar el problema de la 'subversión' no era sino la cara más evidente de una gran crisis moral que ponía en evidencia el agotamiento de una modalidad de intervención política identificada como 'demagogia'. Para el periodo que nos ocupa resulta fundamental entender en qué medida y bajo qué lectura histórica el proyecto refundacional que pretendió realizar el Proceso de Reorganización Nacional (PRN) estuvo vinculado a la idea de que una forma de concebir la representación política había llegado a su fin.

En el discurso militar, este diagnóstico se sostiene a partir de la caracterización de la situación previa al golpe de Estado a partir de la conjunción de dos marcos temporales distintos. Por un lado, la crisis de 1976 era situada dentro de un tiempo corto delimitado por la urgente necesidad de reemplazar a un gobierno que, desde la perspectiva militar, era más parte del problema que de la solución. Por el otro, esta crisis también se inscribía en un tiempo caracterizado por el progresivo abandono de los valores y tradiciones genuinamente democráticas y argentinas.

El entrecruzamiento de estas dos escalas en el discurso militar fue clave en la justificación de la intervención de las Fuerzas Armadas luego del golpe. Apelando al tiempo corto se buscó mostrar que la crisis del gobierno de 1976 se expresaba en hechos muy concretos en los cuales se apoyaba la veracidad del diagnóstico. Dentro del discurso militar, el vacío de poder en el partido gobernante, el desorden económico, la corrupción generalizada, así como la violencia desplegada por las organizaciones armadas de izquierda y un sindicalismo presuntamente infiltrado por ideologías extranjeras, eran tópicos que se ofrecían como datos 
objetivos y a la vista de todos. Sin embargo, estos hechos encuentran en la segunda codificación temporal su especificidad dentro del diagnóstico militar: "cada uno de esos signos marcó el final de una etapa que perdía inexorablemente vigencia, y que era incapaz de generar una alternativa de reemplazo" (Videla, 1976: 9). La crisis del gobierno peronista en 1976 funcionaba como evidencia irrefutable del agotamiento de un periodo histórico cuyo contenido axiológico, cultural y político había llegado a su fin. Ante esta justificación el gobierno militar y su proyecto político adquirieron un carácter refundacional en tanto impugnaba a la sociedad como un todo organizado a partir de ciertos principios que habían entrado en una fase crítica. En el discurso con el cual Jorge Rafael Videla asume la primera magistratura de facto, el eslabonamiento de las dos escalas de la crisis aparece así:

\footnotetext{
Pero debe quedar claro que los hechos acaecidos el 24 de marzo de 1976 no materializan solamente la caída de un gobierno. Significan, por el contrario, el cierre definitivo de un ciclo histórico, y la apertura de uno nuevo cuya característica fundamental estará dada por la tarea de reorganizar la Nación, emprendida con real vocación de servicio por las Fuerzas Armadas (Videla, 1976: 7).
}

Desde esta perspectiva, las Fuerzas Armadas entendieron que su misión histórica era hacerse cargo de las instituciones del Estado para "realizar una organización futura que permita el ejercicio de una democracia con real representatividad, sentido federalista y concepción republicana" (Ibídem: 13). El gobierno militar debía engendrar el futuro otorgándose prerrogativas excepcionales para intervenir en el presente.

Ahora bien, estas dos escalas temporales en las que se sostenía el diagnóstico militar tenían un denominador común: la demagogia. A través de esta categoría, el largo proceso de pérdida axiológica y la crisis de 1976 forman un único y homogéneo periodo que debía concluir con el arribo del PRN. En efecto, para las Fuerzas Armadas, el largo ciclo histórico que se dejaba atrás estaba indisolublemente vinculado a una cierta forma de ejercer la representación política en Argentina. La categoría demagogia funciona en el diagnóstico militar como contra-concepto en la medida en que permite generar un contraste y establecer una frontera identitaria respecto a un amplio conjunto de actores, valores y prácticas con las que se busca diferenciar el proyecto refundacional del PRN. De esta manera, la categoría de demagogia no servía tanto para identificar a un actor particular, sino que señalaba una modalidad de intervención política que era coextensiva al espacio político en su totalidad: "Un factor había contribuido 
notablemente a este deterioro de nuestro estilo de vida democrático, y si hubiera que definirlo en una sola palabra, diría que es demagogia (Videla, 1976: 45).

Desde el punto de vista militar, la demagogia era el mecanismo responsable de introducir una constante distorsión de los valores genuinamente democráticos al subordinar toda discusión sustantiva a un criterio puramente cuantitativo. En este registro lo que subyace es una conceptualización negativa sobre la democracia de masas y sus efectos. Problemática ante la cual el PRN se auto interpretará como una solución definitiva. Este malestar se trasluce en el señalamiento de los peligros que entraña el dispositivo electoral. Desde esta postura, la posibilidad de dirimir una discusión política apelando al número y a la construcción de mayorías había entronizado un estilo de conducción que, con tal de ganar la adhesión del pueblo, había provocado una larga decadencia: "la demagogia ha generado la subversión de valores" (Videla, 1976:23). A partir de este diagnóstico, la cuestión a resolver al interior del proyecto refundacional del PRN consistió en buscar la manera de limitar los efectos perniciosos de una democracia de mayorías mediante la creación de un proyecto sustantivo que marque los límites de lo representable (o los 'límites del disenso' como aparece en las propias discusiones de la Junta). Es en torno a este tópico que las tres armas que compusieron la Junta Militar intentaron compatibilizar distintas alternativas de solución. La expectativa de generar un Movimiento de Opinión Nacional (MON) que perpetuara los valores procesistas más allá del gobierno militar se inscriben dentro de esta problemática (4).

Esta problematización de la democracia de masas a la que arriba el discurso militar se va a constituir en una aporía insuperable, cuando luego de 1979 la Junta Militar intentó precisar las directrices que debían orientar la pretendida refundación. De cara al primer diálogo político realizado en 1980, esta valoración y el ímpetu refundacional asociados a ella mediarán y condicionarán los acercamientos entre las Fuerzas Militares y las fuerzas políticas civiles (5). De manera un tanto paradójica, el diálogo convocaba a los 'partidos políticos preexistentes' como eran llamados en la nomenclatura militar- a participar en su propia liquidación. Como efecto no deseado, este acercamiento implicó un reconocimiento a estos partidos como actores legítimos en la fase de institucionalización y puso en marcha un proceso de reorganización partidaria que encontró en el surgimiento de la Multipartidaria un momento climático y un punto de inflexión en el espacio político argentino (6).

\section{La Multipartidaria y la representación común de las mayorías populares}


Con un comunicado de prensa publicado el 14 de julio de 1981 en los principales diarios del país, se formalizó la creación de la Multipartidaria. El documento aparece firmado por la Junta Política Convocante integrada por la Federación Demócrata Cristiana, el MID, el Partido Intransigente, el Partido Justicialista y la Unión Cívica Radical. En sus últimas líneas, tras justificar la decisión de crear el nucleamiento multipartidario se afirma lo siguiente: "De esta manera damos por iniciada la etapa de transición hacia la democracia, objetivo que constituye nuestra decisión intransferible e irrevocable" (Multipartidaria, 1982: 10). Si al inicio del diálogo político convocado por Videla los partidos políticos se mostraron a la expectativa de una posible concertación con los militares, para mediados de 1981 los cinco principales partidos políticos de la Argentina declaraban unilateralmente el inicio de la transición a la democracia (Velázquez, 2015).

El surgimiento del nucleamiento multipartidario marcó un punto de inflexión en el espacio político. Diversos analistas de la época reconocieron su surgimiento como el hecho político de más trascendencia desde el golpe de Estado de 1976 (7). Para el arco civil partidario significó contar con un instrumento adecuado para hacer frente a la amenaza refundacional del gobierno militar. Carlos Contín de la UCR destacaba que los partidos reunidos en la Multipartidaria constituían al 80 por ciento del electorado. Lo cual, desde su perspectiva, convertía inmediatamente al nucleamiento en un factor político que la Junta Militar debía considerar. Esto, sin embargo, no sucedió. La Junta Militar se negó a reconocer a la Multipartidaria como un actor legitimo en la fase de institucionalización y ante esta situación el organismo multipartidario fue adquiriendo un tono cada vez más confrontativo. El punto climático de este creciente antagonismo se dio días antes del desembarco militar en Malvinas, cuando la Multipartidaria realizó en Paraná el primer acto partidario multitudinario desde el golpe de Estado de 1976.

La iniciativa que dio pie al surgimiento de la Multipartidaria fue promovida por Ricardo Balbín. Hasta entonces, el dirigente radical se había mostrado reacio a promover este tipo de acuerdos. El cambio de opinión se puede explicar atendiendo tanto a la dinámica que en aquel momento adquirió la interna militar, como a movimientos que al interior de los partidos fueron colocando en la agenda partidaria la conformación de un acuerdo de este tipo. En efecto, la presidencia de facto de Roberto Eduardo Viola había iniciado su gestión con un discurso de apertura que se tradujo en la decisión de incorporar cuadros civiles al gobierno. En un contexto en el cual la pugna entre las tres armas se encontraba en su punto más álgido, este sesgo aperturista no fue bien recibido por el ala más dura de la Junta Militar. En un intento por calmar las aguas, Viola declaró que el próximo presidente sería un militar designado por la Junta. Para 
los partidos políticos esta postergación de los plazos de apertura fue tomada como una claudicación intolerable. Balbín calificó los dichos de Viola como "agresión a la civilidad" ( La Nación, 11 de julio de 1981). Declaración que contrastaba con el tono moderado que había mantenido desde el inicio del diálogo político convocado en 1979 por la Junta Militar. Ante esta misma situación el justicialismo emitió un duro documento en el que se afirmaba que "el Proceso de Reorganización Nacional ha fracasado definitivamente" y exhortaba a las Fuerzas Armadas a "anunciar los plazos en que retornarán a su misión específica, devolverán la soberanía al pueblo y se restablecerán las instituciones de la Constitución Nacional" (La Nación, 1 de julio de 1981).

Como decíamos, la decisión de Balbín de promover un acuerdo multipartidario que incluyera al peronismo tuvo también sus condicionantes en el frente partidario. La idea de generar un acuerdo de esta índole se fue generando desde las bases del radicalismo y del peronismo. Este proceso incluyó una escala provincial particularmente relevante. En junio, Balbín recibió una carta firmada por cincuenta dirigentes radicales en la cual se le pedía que "promueva las coincidencias con todas las fuerzas políticas democráticas y demás sectores de nuestra sociedad" con el objetivo de "unificar el reclamo del regreso al estado de derecho, la vigencia de la soberanía popular y la convocatoria a elecciones" (Acuña, 1984: 212). A principios de año, militantes radicales y justicialistas habían emitido un documento conjunto en el que se convocaba a "todas las fuerzas políticas sociales para la elaboración de un plan de emergencia nacional que revierta la injusticia situación económica y nacional" (La Nación, 8 de junio 1981) (8). En el mismo sentido, en Villa Tototal, Córdoba, se realizó una reunión multipartidaria convocada por el radicalismo y el peronismo provinciales. De manera semejante, en la provincia de Buenos Aires las juventudes de cinco partidos habían dado a conocer un acuerdo en el que se comprometían a emprender acciones conjuntas con el objetivo de defender los derechos humanos, exigir el levantamiento del estado de sitio y el regreso a la soberanía popular.

Una vez constituida, la función que debía cumplir la Multipartidaria fue un tema de disputa ante el cual es posible identificar dos posicionamientos generales. Las alternativas fluctuaban entre aquellos que veían al nucleamiento con capacidad suficiente para conducir la apertura política y quienes consideraban que el organismo podía servir como mecanismo de presión para acordar una salida concertada con los militares. La disyuntiva cortaba transversalmente a los partidos reunidos en la Multipartidaria y si bien es cierto que la posterior estrategia de movilización pareciera indicar que las posiciones más a favor de oponer una oposición directa a 
la dictadura se fueron imponiendo, la realidad es que hasta la derrota militar en Malvinas se mantuvo abierta la posibilidad de una negociación con el gobierno militar.

El grupo del radicalismo vinculado al alfonsinista Movimiento de Renovación y Cambio (MRyC) se mostraba más bien optimista respecto a las posibilidades que entrañaba el novel nucleamiento. Para Alfonsín, con el surgimiento de la Multipartidaria la iniciativa jugaba ahora a favor del polo civil por lo que se estaba en condiciones de generar un proyecto de transición diferente al de las FF.AA. Es particularmente relevante que Alfonsín constantemente recurriera al clivaje popular/antipopular como criterio para distinguir entre los proyectos de transición de ambos polos. En efecto, Alfonsín insistía en anteponer el vínculo considerado como inherente entre democracia y mayorías populares a la relación que la dictadura había establecido con una minoría significada por el dirigente radical como "oligarquía". En este sentido, Alfonsín afirmaba que:

La Convocatoria a través de la declaración o el comunicado que se ha efectuado y también en cuanto a la posición del Radicalismo en su origen tiene un objetivo fundamental, la recuperación de la democracia (...) Si las FFAA comprenden la necesidad de romper la alianza con las minorías y sumarse a los requerimientos de la mayoría, mucho mejor, nosotros debemos de trabajar para superar cualquier tipo de antagonismos, pero si no lo entendieran de esta manera, tendrían que convertirse en ejército de ocupación en su propio País, porque nosotros vamos a dar testimonio de nuestra decisión de recuperar la democracia en la Argentina (Revista Línea, 1981: p. 25).

Esta identificación del gobierno militar como agente de representación de intereses antipopulares acompañó el tránsito de la Multipartidaria hacia posiciones más confrontativas. En un documento publicado en enero de 1983 titulado La Paz no tiene precio: es la Constitución Nacional, este contrapunto aparece de la siguiente manera:

las nuevas autoridades no sólo han ignorado la propuesta de las mayorías nacionales, expresadas a través de la Multipartidaria, sino que están profundizando una política económica y social que responde únicamente a una pequeña minoría tradicionalmente opuesta a los intereses del pueblo (Multipartidaria, 1982: 188).

En un sentido semejante al de Alfonsín, Conrado Storani también integrante del MRyC, consideraba al nucleamiento político como una legítima expresión en defensa de los intereses populares. Desde la perspectiva del dirigente radical, el papel de la Multipartidaria debía ser el 
de contener y canalizar el descontento social, movilizando al pueblo en la demanda de apertura y democratización. Para Storani, la Multipartidaria era "la expresión más importante de los últimos años en el campo político argentino" (VV. AA, 1981: 53) y le otorgaba un lugar central para traducir el descontento social acumulado en un efecto político concreto:

la explosión social tendrá que ser conducida por la Multipartidaria para impedir el caos. Para conducirla a la Plaza de Mayo si es necesario; para decirle al gobierno: aquí está el pueblo argentino, reclamando la restitución del cauce natural de la Argentina, para cambiar totalmente (Ídem).

La advertencia sobre las casusas sociales generadas por las medidas económicas implementadas por el gobierno militar servía para justificar y legitimar la práctica representativa de los partidos políticos y reivindicar su posición frente a las mayorías populares agraviadas. Las posiciones de los dirigentes vinculados el MRyC contrastaban con la postura de Balbín quien consideraba que: "Las FF. AA tienen que considerar esto [por la Multipartidaria] como un elemento de ayuda al éxito del Proceso" (Revista Línea, 1981).

Por su parte, Deolindo Bittel, vicepresidente del justicialismo, se inclinaba a ver al nucleamiento como un medio para acelerar los tiempos de apertura del Proceso y reconocía en el acuerdo con el radicalismo una vía importante para hacer frente de manera conjunta a la crisis social y económica. Otra postura dentro del justicialismo la ofrecía Federico Robledo, para quien la negociación con los militares seguía siendo el mejor esquema para lograr una transición a la democracia. Desde su perspectiva, la Multipartidaria era un paso importante en este sentido pues implicaba contar con instrumento adecuado para pactar de manera cohesionada un gobierno transicional. El nucleamiento debía dar paso a "un gobierno de unión nacional, que integre un poder ejecutivo de coalición constituido por el poder militar y los partidos políticos". Antonio Cafiero, figura central del peronismo durante el primer gobierno de la posdictadura, pensaba, por el contrario, que la Multipartidaria formaba parte de manera exclusiva del espacio político civil y que el nucleamiento debía continuar incluso aún conseguida la transición a la democracia.

Yo soy de los que piensan que [la Multipartidaria] deberá continuar funcionando durante el próximo gobierno constitucional. Visualizo incluso la creación de un consejo asesor multipartidario, del presidente de la república. (...) Hay determinadas decisiones que, por su importancia, habrá que tomarlas con el consenso de toda la civilidad, de todos o casi todos los partidos (Cafiero, 1983: 191). 
Tal vez el registro que mejor muestre las expectativas que en ciertos sectores generó la Multipartidaria la encontremos en una conferencia organizada por la editorial Cid en la cual participaron el historiador peronista José María Rosa, Oscar Alende del Partido Intransigente y Conrado Storani de la UCR. Al ser cuestionados sobre las posibilidades del acuerdo multipartidario concretado, Alende, de pasado radical, proponía pensarlo en términos de un Tercer Movimiento Histórico, superador de las experiencias de Yrigoyen y Perón. La fórmula que luego sería repropiada por algunos sectores alfonsinistas durante el primer gobierno de la posdictadura, aquí era utilizada por Alende para dar cuenta de la convergencia de los partidos identificados con la representación de los intereses de las mayorías populares en su oposición frente a la dictadura. Desde su perspectiva, la oposición a un gobierno militar antipopular había abierto la posibilidad de "una confluencia de las discordancias en lo fundamental, en lo que pude implicar la conjunción de los valores nacionales". José María Rosa llegó un poco más lejos al sugerir el advenimiento de un pan-populismo. Por su parte, Storani coincidía con Alende y afirmaba que se estaba

construyendo el poder civil (...) Entonces yo sí creo que puede haber una confluencia fundamental en un gran movimiento popular, lo que no implica en este minuto tocar para nada un tema popular (...) no vamos hablar ni en nombre del peronismo, ni en nombre del radicalismo, ni de la democracia cristiana, vamos a hablar en nombre del pueblo argentino (VV. AA, 1981: 69-77).

A los ojos de las fuerzas civiles y políticas afines al PRN, la Multipartidaria no era sino una nueva expresión de aquello que se quería dejar atrás. Para la Fuerza Federalista Popular (FUFEPO), la convocatoria multipartidaria "expresa lo que ha sido el fracaso del país" (La Nación, 28 de julio de 1981) y se negó a adherirse a ella. En un sentido semejante, la Sociedad de Estudios y Acción Ciudadana (SEA) presidida por Ernesto Parellada afirmó que los partidos reunidos en la Multipartidaria: "son la más auténtica expresión de lo que ha quedado atrás" ( $\mathrm{La}$ Nación, 18 de enero de 1982). En el centro de estas críticas estaba la caracterización del radicalismo y el peronismo como partidos populistas responsables de la larga crisis argentina.

\section{El espacio político después de Malvinas: la democracia en disputa}


Luego de la derrota militar en Malvinas, la correlación de fuerzas cambió abruptamente. Esta nueva inflexión en el espacio político argentino también significó que la estrategia de movilización iniciada por la Multipartidaria en marzo de 1982 entrara en un paréntesis que sólo se cerraría para dar cauce a la actividad partidaria de cara a las elecciones de 1983. La Multipartidaria fue rápidamente colocada en el olvido, pero es una experiencia fundamental en el reposicionamiento de los partidos políticos como centro de la actividad política y un antecedente inmediato de la importancia que adquirió el pluralismo en el vocabulario político que se consolidó durante el primer gobierno de la posdictadura.

Entre 1982 y 1983 la oposición entre democracia y dictadura adquirió la relevancia que usualmente se le reconoce como rasgo esencial de la transición argentina. El problema de los derechos humanos pasó de ocupar un lugar marginal a convertirse en un problema que claramente marcaba dos legitimidades en disputa. Raúl Alfonsín fue el que mejor interpretó esta situación y asumió una posición que lo destacó del peronismo, este último más precavido en tanto se pensaba favorito para ganar el cercano proceso electoral. Para el gobierno militar no pasó desapercibido que el clivaje democracia/dictadura era ya la referencia que organizaba el juego político e intervino presentándose como el factor que podía asegurar que la inminente transición se realizara en un marco de estabilidad.

En un comunicado de prensa dado a conocer en febrero de 1983, la creciente relevancia que adquirió la discusión sobre las secuelas de la represión era caracterizada por la Junta Militar como una campaña "destinada a desprestigiar a las fuerzas armadas" que "lejos de facilitar el deseado reencuentro nacional, aspiración de las Fuerzas Armadas y en cuya consecución se hallan empeñados tanto la Iglesia como todos los ciudadanos que desean la vigencia plena de la democracia y la paz en la república, ahondan antinomias e interfieren con la institucionalización del país" (9). En un contexto de creciente clima anti-dictatorial (Franco 2014), la Junta Militar diseñó una estrategia de persuasión con el objetivo de modificar las coordenadas del espacio político.

La estrategia implementada por las FF. AA fue pensada con el objetivo expreso de "crear una polarización distinta, enfrentando a la democracia contra el totalitarismo [subversivo] o lo que es lo mismo, la normalización de paz y orden opuesta a su fracaso" (10). El resultado esperado era situar al gobierno militar "a la cabeza de la ciudadanía que pretende democratizar la República" (11). Para ello el gobierno recurrió nuevamente a su legitimidad como bando victorioso en el combate contra la subversión, movilizando el fantasma de un posible rebrote de violencia. La idea era entonces situarse por encima del clivaje dictadura/democracia y 
mostrarse como garante de estabilidad y de continuidad institucional en la futura democracia argentina. El clivaje democracia/dictadura debía ser reemplazado por el de orden/violencia. Una de las medidas discutida por la Junta Militar para contribuir a convertir en "realidad esa polarización democracia-antidemocracia" (12) fue hacer uso de los medios de comunicación con el objetivo de vincular la lucha contra las organizaciones armadas de izquierda con el contexto de terrorismo internacional. Se proponía así el desarrollo de una campaña que se difundiera "en noticieros de TV, radiales, imágenes y comentarios relativos a acciones terroristas a nivel internacional (...) relacionándolas coherentemente con hechos similares producidos por el terrorismo local, y haciendo un análisis comparativo con datos disponibles, donde se resalte la magnitud del fenómeno local" (13).

Otra acción dispuesta dentro de la contraofensiva militar giró en torno a cómo aprovechar la documentación obtenida luego de la detención y asesinato del jefe de grupo armado Montoneros, Raúl Clemente Yaguer. La Junta Militar se propuso

\footnotetext{
explotar, a partir de este momento, toda información obtenida como consecuencia de la muerte del DT [delincuente terrorista] Yaguer, accionando sobre la dirigencia política (...) a fin de incrementar el prestigio de las FF. AA y contribuir a la pacificación nacional, base imprescindible de la normalización institucional de la república (14).
}

En el posterior informe dado a conocer al público, se afirmaba haber encontrado documentación que probaba que Montoneros estaba planeando atentados en contra de importantes referentes del peronismo como Saúl Ubaldini, Lorenzo Miguel, Juan José Taccone y Ángel Federico Robledo; se hacía referencia también a notas en las que se hablaba de una negociación entre Lorenzo Miguel y el Ejército (Ferrari, 2013: 130).

Aun advirtiendo las condiciones cada vez menos favorables para el gobierno de facto, la Junta Militar seguía pensando que podía asegurar una transición que incorporara algún esquema de participación de las Fuerzas Armadas en el próximo gobierno constitucional. En el documento titulado Bases políticas para la concertación, la Junta Militar fijaba para los primeros meses de 1984 la fecha en que la fase de institucionalización debía concluir (15). Para llegar a este fin se proponía "concertar con los sectores representativos del quehacer nacional", con el objetivo de "asegurar una transferencia armónica y ordenada al nuevo gobierno, que garantice su estabilidad constitucional". En dicho documento se insiste en la presencia constitucional de las Fuerzas Armadas en el próximo gobierno nacional a parir de dos medidas a. la integración de las mismas en el gabinete nacional del gobierno resultante del proceso de institucionalización y 
b. la creación del Consejo Nacional de Seguridad que asegurara la continuidad de la victoria contra la subversión. Para las Fuerzas Armadas el punto central que permitiera una transición que cumpliera con sus objetivos seguía siendo definido en términos de una aludida victoria militar que le otorgaba derecho tutelar sobre la apertura política. En este sentido se establecía que el objetivo era asegurar la "vigencia y proyección de los logros obtenidos por la victoria militar sobre la subversión armada, en su carácter de triunfo logrado por toda la nación" (16).

En el último tramo de la dictadura la cuestión de los derechos humanos ya se percibía como un criterio que permitía marcar diferencias y ubicar a las diversas voces en el espacio público. Adolfo Pérez Esquivel, referente del movimiento por los derechos humanos y ganador del Premio Nobel de la paz en 1980, especificaba la centralidad del tópico haciéndolo contrastar con otro clivaje caro a la historia política argentina: "la opción liberación o dependencia implica hoy terrorismo estatal o democracia popular. Los partidos políticos y todas las organizaciones democráticas deben asumir en sus programas la defensa de los derechos humanos" (Ferrari, 2013: 129).

De esta manera, luego del diálogo político de 1980 con el cual la Junta Militar pretendió dar inicio a la refundación del espacio político argentino y que tuvo como desenlace el surgimiento de la Multipartidaria, se inició un proceso en el que se condensaron una serie de oposiciones y desplazamientos tras los cuales finalmente quedaron emparejados, por un lado: democracia, defensa de intereses populares y derechos humanos; por el otro, dictadura, minoría favorecida y represión.

\section{Conclusiones: y la refundación por otros medios}

A lo largo de nuestro recorrido hemos identificado ciertos puntos de pasaje en la conformación del espacio político argentino entre 1980 y 1983. En estas transformaciones, la práctica representativa de los partidos políticos resulta fundamental en tanto habilita condensaciones semánticas y desplazamientos discursivos que modifican las coordenadas que articulan el juego político. Al término de este trayecto, el reclamo por una apertura política engloba una serie de demandas que en un principio aparecen disociadas de esta cuestión. El sentido que adquiere el clivaje democracia/dictadura aparece así sobre determinado por esta trayectoria previa. Si la transición a la democracia entrañó la posibilidad de que surgiera un discurso que interpretara la apertura de 1983 como una ruptura, fue en parte debido a que la actividad 
política durante estos años colaboró a procesar los estados de ánimo a través de su inscripción en narrativas políticas que le dieron una particular significación.

A mediados de 1981, con el surgimiento de la Multipartidaria, el reclamo por una apertura política se empieza a situar dentro de un creciente antagonismo con el gobierno militar. Este cambio estuvo sustentado en un mutuo reconocimiento de los partidos políticos reunidos en la Multipartidaria; convergencia que tuvo como una de sus condiciones fundamentales la identificación de un sujeto popular al que había que representar en común frente al gobierno militar. Posibilitada por la crítica a la política económica implementada por las FF. AA, la oposición popular/antipopular antecede y da sentido al clivaje democracia/dictadura.

Tras la derrota militar en el Atlántico Sur la oposición entre democracia y dictadura se instaló definitivamente. Alrededor de esta dicotomía se condensó buena parte de la semántica previa. La disputa que organizó el espacio político post-Malvinas opuso a militares y a partidos políticos en torno a cuál de estos polos podía ofrecer las mejores condiciones de estabilidad ante la inminente apertura política. El reclamo por los derechos humanos resultó especialmente delicado para el gobierno militar, pues puso en entredicho su identidad como bando victorioso en el combate contra las organizaciones armadas de izquierda. Para este momento la democracia se consolida como lo opuesto a la dictadura, en la medida en que es capaz de condensar toda la semántica previa.

Entre 1980 y 1983 se observa un cambio fundamental en el lenguaje de los partidos políticos. Durante estos años, el concepto de democracia se carga de un significado que permite procesar y marcar una diferencia radical con el gobierno militar. Esta semántica resulta central para precisar el sentido que adquirió el clivaje dictadura/democracia durante la transición. Si al inicio del diálogo político convocado por el gobierno militar en 1980 el reclamo por la apertura política aparece subordinada a otras demandas que eran percibidas como más urgentes 0 condicionantes de esta apertura, luego de la derrota en Malvinas el reclamo por el regreso a la democracia se convierte en la única posibilidad de resolver las demandas que se fueron acumulando durante los últimos años de la dictadura. Restituir la contingencia del periodo significa mostrar hasta qué punto fue -durante este proceso de desplazamientos y condensaciones de sentido- que el concepto de democracia quedó ligado a una serie de mandatos y expectativas que se debían cumplir en su interior. Lo que se empieza a jugar en el espacio político después de Malvinas es la capacidad de una sociedad democrática para autoinstituirse. El discurso rupturista al que hemos aludido viene a presentarse como una alternativa de solución a este problema. 


\section{Notas}

(1) En La dictadura militar 1976/1983. Del golpe de Estado a la restauración democrática (2011) Marcos Novaro y Vicente Palermo dan una interpretación de los últimos años de la dictadura en la que los partidos políticos son presentados como agentes que esperan pacientemente la implosión del régimen de facto. "La de 1982-1983 -afirman los autores- no era una transición arrancada por luchas y movilizaciones contra la dictadura (...) Se trataba esencialmente del resultado de la crisis interna del régimen, crisis generada más por omisión que por acción de los grupos sociales y políticos frente al autoritarismo y por la derrota militar" (Novaro y Palermo, 2011: 469). Esta interpretación nos hace perder de vista un importante registro de recomposición de la actividad partidaria que tuvo lugar durante los últimos años de la dictadura. Consideramos que abordar este proceso resulta fundamental para comprender en qué medida la práctica representativa ejercida por los partidos políticos influyó en la constitución del espacio político de la transición.

(2) Para una aproximación más específica sobre esta perspectiva de la representación política, ver Velázquez, 2017.

(3) Este documento sirvió de marco a la llamada "fase de institucionalización" iniciada formalmente con la publicación de dicho documento y la posterior convocatoria al diálogo político. Para la confección de este documento rector la Junta Militar realizó un proceso de compatibilización en el cual las tres armas que la conformaban presentaron proyectos individuales, que luego de su discusión debía revelar puntos en común.

(4) El MON fue pensado como el mecanismo fundamental que debía asegurar la continuidad de la refundación que la dictadura pretendía generar. Sin embargo, los documentos discutidos en el proceso de compatibilización de cara a la fase de institucionalización, nos muestra que no existía un consenso respecto a qué debía ser este MON y cuál debía ser la estrategia para constituirlo.

(5) Para una mirada general sobre los discursos de legitimidad de las FF. AA. entre 1976 y 1983, recomendamos el artículo de Joaquín Baeza Belda (2016).

(6) Par un análisis sucinto del contexto abierto por el diálogo político y las condiciones en las cuáles surgió la Multipartidaria, ver Velázquez, 2015.

(7) Ver, por ejemplo, la editorial de La Nación del 20 de enero de 1982.

(8) Paradójicamente, ael año siguiente los intentos para conformar la Multipartidaria provincial en Córdoba encontraron diversas dificultades. En particular, al interior de la UCR Córdoba dirigida por Angeloz, algunos sectores darían su negativo con el argumento de que sería ceder la individualidad del radicalismo ( La Nación, 8 de marzo de 1982).

(9) Junta Militar (2013), anexo del Acta 247, 10 de febrero de 1983.

(10) Junta Militar (2013), acta № 261 del 19 de mayo de 1983.

(11) Junta Militar (2013), acta № 261 del 19 de mayo de 1983.

(12) Junta Militar (2013), anexo del acta № 256 del 14 de abril de 1982.

(13) Junta Militar (2013), anexo del acta № 256 del 14 de abril de 1982.

(14) Junta Militar (2013), acta Nº 261 del 19 de mayo de 1983.

(15) Junta Militar (2013), anexo del acta 240, 10 de noviembre de 1982.

(16) Junta Militar (2013), anexo del acta 240, 10 de noviembre de 1982.

\section{Bibliografía}


AA. VV. (1981). El ocaso del "proceso". Oscar Alende, Conrado Storani, Néstor Vicente y José María Rosa. Buenos Aires: El Cid Editor.

Aboy Carlés, G. (2001). Las dos fronteras de la democracia argentina. La reformulación de las identidades políticas de Alfonsín a Menem. Rosario: Homo Sapiens.

Aboy Carlés, G. (2015). Persistencias del populismo. En Cantamutto, F.; Velázquez, A. y Costantino, A. (coordinadores). De la democracia liberal A la soberanía popular (Vol. 2). Buenos Aires: CLACSO.

Acuña, M. (1984). De Frondizi a Alfonsín: la tradición política del radicalismo (Vol. 2). Buenos Aires: Centro Editor de América Latina.

Armada Argentina (1977). Consideraciones sobre el proceso de institucionalización y el Movimiento de Opinión Nacional. Recuperado de http://www.cipol.org/pdfs/Planespol/Plan_de_la_Armada.pdf

Baeza Belda, J. (2016). La concertación. El último intento de legitimación de la dictadura argentina (1982). História Unicap, 3(5).

Cafiero, A. (1983). Desde que grité i Viva Perón! Argentina: Pequén Ediciones.

Canelo, P. (2016). La política secreta de la última dictadura argentina (1976-1983). Argentina: Edhasa.

Canelo, P. (2008). El Proceso en su laberinto: la interna militar de Videla a Bignone. Buenos Aires: Prometeo Libros Editorial.

Ejército Argentino (1978). Bases políticas del Ejército para el Proceso de Reorganización Nacional. Disponible en http://www.cipol.org/documentos_desclasificados.php

Ferrari, G. (1983). El año de la democracia. Argentina: Editorial Planeta.

Franco, M. (2014). El complejo escenario de la disolución del poder: militar en la argentina: la autoamnistía de 1983. Contenciosa, I(2).

Franco, M. (2016). Los derechos humanos en los años 80 dictatoriales: un vieja problema bajo nuevas preguntas. Ponencia presentada en VII Jornadas de trabajo de Historia Reciente, Universidad Nacional de Rosario.

Fuerza Aérea Argentina (1978). Propuesta política de la Fuerza Aérea. Disponible en: http://www.cipol.org/documentos_desclasificados.php

Gonzalez Bombal, I. (1991). El diálogo político: la transición que no fue. Buenos Aires: CEDES. Junta Militar (1980) Documentos básicos y bases políticas de las Fuerzas Armadas para el Proceso de Reorganización Nacional, Buenos Aires, 1980. Disponible en: http://www.ruinasdigitales.com/ 
Junta Militar (2013). Actas de la Dictadura: documentos de la Junta Militar encontrados en el edificio Cóndor, Ciudad Autónoma de Buenos Aires, Ministerio de Defensa. Recuperado de http://www.mindef.gov.ar/archivosAbiertos/centroDeDocumentos.php?documentos=edif icioCondor

Landi, O. (1985). El discurso sobre lo posible: la democracia y el realismo político. Buenos Aires: Centro de Estudios de Estado y Sociedad.

López Saavedra, E. (1984). Testigos del "proceso" militar. Buenos Aires: Centro Editor de América Latina.

Revista Línea (1982). 13, s. d.

Multipartidaria (1982). La propuesta de la Multipartidaria. Buenos Aires: El CID editor.

Novaro, M. y Palermo, V. (2011). La dictadura militar 1976/1983. Del golpe de Estado a la restauración democrática. Buenos Aires: Paidós.

Quiroga, H. (2004). El tiempo del Proceso: conflictos y coincidencias entre políticos y militares 1976-1983. Rosario: Homo Sapiens Ediciones.

Rosanvallon, P. (2003). Para una Historia Conceptual de lo político. México: Fondo de Cultura Económica.

Rosanvallon, P. (2004). El pueblo inalcanzable. Historia de la representación democrática en Francia. México: Editorial Mora.

Velázquez Ramírez, A. (2015). De la concertación a la Multipartidaria: el espacio político partidario en los albores de la transición a la democracia en Argentina (1980-1981). Revista Contemporánea, 1, pp. 1-28.

Velázquez Ramírez, A. (2017). Pensar la representación política como ciudadanía: notas para un debate histórico conceptual. Andamios, 14(35), pp. 43-69. Recuperado de https://andamios.uacm.edu.mx/index.php/andamios/article/view/571/918 